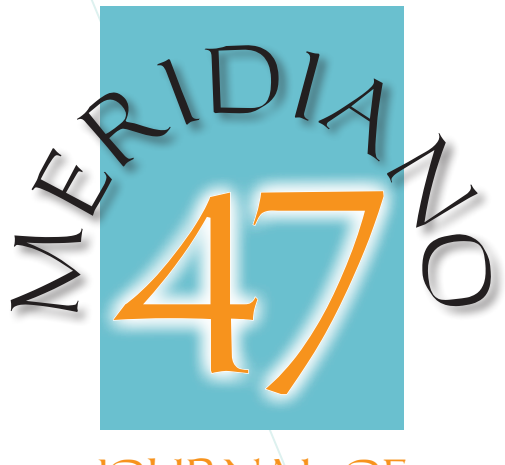

JOURNAL OF

GLOBAL STUDIES

ISSN 1518-1219

http://www.meridiano47.info

\section{Alcindo Fernandes Gonçalves}

Universidade Católica de Santos,

Santos - SP, Brazil (alcindo@unisantos.br).

\section{Arthur Marques Silva}

Universidade Católica de Santos, Santos - SP, Brazil (amsilva@unisantos.br).

iD ORCID ID:

orcid.org/0000-0002-7252-874X

\title{
Governança global e militarização do espaço sideral
}

\section{Global Governance and outer space militarization}

DOI: http://dx.doi.org/10.20889/M47e20009

Recebido em 22 de janeiro de 2019 Aprovado em 15 de abril de 2019

\section{Resumo}

O presente artigo procura demonstrar a possibilidade da aplicação dos instrumentos de governança global para resolver os problemas relacionados à militarização do espaço sideral. Após um breve histórico sobre a questão, é analisado se os instrumentos da governança global, inspirados no "Ottawa Process", seriam aplicáveis na resolução dos problemas no citado ambiente, reforçando a sua utilização como via de consenso global.

\begin{abstract}
The present article aims to demonstrate the possibility of applying mechanisms of global governance to solve the problems related to the militarization of outer space. Initially a brief history was made on the question. Subsequently, it was analyzed how the global governance mechanisms, inspired by the "Ottawa Process", would be applicable in solving the problems in the mentioned environment, reinforcing its use as a way of global consensus.
\end{abstract}

Palavras-Chaves: Militarização do Espaço Sideral; Governança Global, Ottawa Process.

Keywords: Outer space militarization; Global Governance, Ottawa Process.

\section{Introdução}

- This is an open-access article distributed under the terms of a Creative Commons Attribution License, which permits unrestricted use, distribution, and reproduction in any medium, provided that the original author and source are credited.

- Este é um artigo publicado em acesso aberto e distribuído sob os termos da Licença de Atribuição Creative Commons, que permite uso irrestrito, distribuição e reprodução em qualquer meio, desde que o autor e a fonte originais sejam creditados.

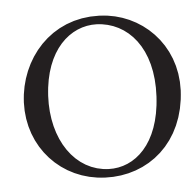
conceito de governança global difundiu-se de tal maneira que sua atual esfera de influência abrange as mais diversas áreas do conhecimento, em um processo que vem forçando os sujeitos clássicos do Direito Internacional Público, os Estados, a dividirem suas prerrogativas de soberania com outros atores internacionais.

De fato, governança global pode ser compreendida como um processo em que outros atores, como organizações internacionais, 
empresas multinacionais, organizações não governamentais (ONGs) e entes subnacionais, passam a gozar de ampliado poder de participação em várias questões de interesse comum, no qual prevalece o consenso e a persuasão, com a finalidade de resolver problemas que concernem a todos. A governança é um processo em que a participação estatal está incluída, porém não se limita a ele, haja vista dar-se voz aos demais atores, tal como se consubstanciam as ONGs e o setor privado (GONÇALVES, COSTA, 2011).

De fato, é possível constatar que a atuação da sociedade civil e da comunidade epistêmica vêm abrindo novos caminhos em todas as fases em vários temas, como aqueles relacionados ao meio ambiente - formulação do problema, discussão sobre alternativas de solução, institucionalização, tomada de decisões e monitoramento e fiscalização - que antes eram exclusivos da ação dos Estados.

Nesta esteira, a alçada da segurança e defesa, tida até os dias atuais como uma das áreas tradicionais de atuação dos Estados, vem sofrendo um processo de penetração de ideias advindas da sociedade civil, dando maior lastro à ideia de aplicação da governança global.

É diante deste panorama que se insere uma das mais recentes áreas de aplicação da governança global, que é o campo da militarização do espaço sideral, zênite dos assuntos de defesa e atualmente em voga diante das mais diversas declarações e demonstrações expedidas pelas grandes potências.

O presente artigo pretende, dessa maneira, analisar a aplicação do conceito de governança global ao tema da militarização do espaço sideral, verificando suas possibilidades e limites. O objeto do trabalho pode assim ser definido como a averiguação sobre a possibilidade de instrumentalizar o citado fenômeno com a finalidade de encontrar soluções para o tema.

\section{Militarização do espaço sideral: dos primórdios ao estado atual}

A exploração do espaço sideral é ainda um campo razoavelmente novo para a humanidade. Produto direto da disputa ideológica da Guerra Fria, a disputa pelo controle do espaço sideral é vista por muitos autores como a fronteira final dos conflitos humanos.

Iniciada de maneira não diretamente bélica, as venturas ao redor da órbita terrestre tiveram como inicial objetivo a colocação de corpos artificiais (satélites), os quais representariam o ápice da supremacia tecnológica, ferramenta de propaganda tanto do lado capitalista norte-americano como do lado socialista da antiga União Soviética. Tida como o zênite, a chegada do homem à Lua se mostrou como bastião da propaganda dos Estados Unidos e, na visão de alguns, como prova inequívoca da vitória norte-americana na exploração do espaço sideral.

Com o passar do tempo as duas superpotências se tornaram hábeis em não somente circundar o globo e estudar os efeitos da falta de gravidade ou as intercorrências que o vácuo poderia causar em determinados objetos e seres vivos, mas também foram construindo sua expertise em encontrar novas utilidades para o espaço sideral.

Assim, como já ocorrera com diversas outras áreas de estudo da humanidade, em pouco tempo tal esfera pouco explorada se mostraria terreno fértil para dar guarida a interesses militares e geopolíticos. 
De maneira pouco alardeada, ambos os lados começaram a desenvolver tecnologias que pudessem se valer do terreno espacial a fim de servir aos interesses militares de dissuasão e propaganda, colocando em órbita satélites que passaram a ter o específico fim de vigiar o lado contrário.

Nessa ebulição de tensões e alertada pela comunidade científica em geral, a Organização das Nações Unidas (ONU) deu início às tratativas da construção de tratado que tivesse como escopo a utilização do espaço sideral apenas para fins pacíficos. Dessa forma, em 1967, baseado em discussões já iniciadas no início dos anos 1960 com a Resolução XVIII de 1963, fruto de trabalho do COPUOS (acrônimo na língua inglesa para Comitê sobre os Usos Pacíficos do Espaço Sideral), foi assinado o popularmente chamado Tratado do Espaço Sideral, o qual contou com a participação de vários Estados, incluindo especialmente os Estados Unidos da América (EUA) e a União das Repúblicas Socialistas Soviéticas (URSS).

Em que pese a louvável iniciativa dos Estados para a construção de um tratado que tivesse como específico fim o estabelecimento de princípios que guiassem as nações à exploração pacífica do espaço sideral, o citado tratado acabou por deixar lacunas que passaram a servir aos interesses militares dos Estados.

De fato, em que pese o Tratado do Espaço Sideral ter afirmado, inter alia, que a Lua e outros corpos celestes somente deverão ser utilizados para fins pacíficos e que os Estados possuem a proibição de colocação de armas nucleares e outros tipos de armas de destruição em massa em órbita ou em corpos celestiais ou estacioná-las no espaço sideral de qualquer outra maneira, não existe explicitamente qualquer limitação à utilização do espaço sideral para colocação de armas e equipamentos militares outros que não as armas de destruição em massa em geral (WHITE, 2017; AL-RODHAN, 2018).

Cientes dessa brecha, os Estados, e em particular os EUA, continuaram a desenvolver tecnologias que, tecnicamente, não atentavam contra os preceitos enunciados no Tratado do Espaço Sideral, uma vez que a colocação de satélites artificiais na órbita terrestre e possível estacionamento de armas “comuns" não incorreria contra o texto acordado nas Nações Unidas.

Aqui é importante salientar que as armas e tecnologias que acabam por explorar de maneira bélica o espaço sideral não devem ser compreendidas somente na acepção mais estrita da palavra, ou seja, como meio utilizado para infringir danos a outrem. Com efeito, arma pode ser considerada como

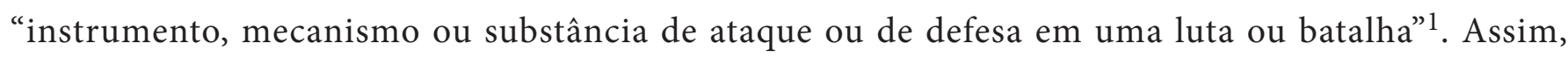
podem facilmente ser incluídos na acepção de 'arma' equipamentos outros que não necessariamente inflijam dano direto à parte contrária, mas sim que sirvam como meios indiretos aos fins militares, como observação e coleta de informações e espionagem em geral.

Ainda trazendo mais dúvidas sobre a conceituação de armas espaciais, autores afirmam que a utilização de armas baseadas na Terra, porém com capacidade de atingir alvos e cumprir objetivos no espaço sideral, também poderia ser enquadrada no conceito de arma espacial (AL-RODHAN, 2018).

Conscientes da questão técnica que possibilitava a contínua exploração militar por parte dos Estados, as Nações Unidas, a pedido da União Soviética, por meio de seu Comitê de Desarmamento,

1 Definição advinda do Dicionário Michaelis. Disponível em: <http://michaelis.uol.com.br/busca?id=GvZq>. Acessado em: 22 abr 2018. 
criaram grupo de trabalho com o específico intuito de estudar maneiras de se evitar com que prosseguisse desenfreada corrida armamentista espacial. Tal grupo recebeu a alcunha de PAROS (acrônimo em inglês para Proposed Prevention of an Arms Race in Space), e iniciou suas atividades formalmente no início dos anos 1980.

Em que pese as reuniões do PAROS estarem ocorrendo desde 1981, o citado grupo de pesquisa não conseguiu realizar avanços significativos. Com efeito, as propostas realizadas no bojo de tal grupo vêm sendo sistematicamente derrubadas pelos EUA, os quais, em maior ou menor grau, mantêm política segundo a qual a elaboração de qualquer sorte de instrumento que vise limitar o seu acesso ao espaço sideral, incluindo-se aqui os usos militares, deve ser terminantemente rechaçada, pois haveria claro descompasso entre o teor de tais instrumentos internacionais com os ideais de soberania norte-americana.

Tal afirmativa pode ser encontrada na leitura das Políticas Espaciais dos EUA, que, após anos de forte oposição à elaboração de regras e/ou princípios que regulassem a atividade militar no espaço sideral, em especial durante as administrações de presidentes do Partido Republicano (PINDJACK, 2011), foram abrandadas durante a administração Obama. Contudo, em razão de uma nova injeção bélica da atual administração Trump, a visão defendida pelos EUA novamente tornou-se voltada a, primeiramente, realizar a defesa de seus interesses nacionais em conjunto com os de seus aliados, conforme se obtém da leitura do memorando "America First Among the Stars" (WHITE, 2017).

Neste sentido é importante observar que os EUA, principais opositores da produção de norma que visa delimitar a exploração bélica no espaço, possuem a sua linha argumentativa baseada em duas frentes, além daquela que defende a ilimitabilidade de seus interesses nacionais em nome da soberania: a) afirmam que na verdade não existe qualquer sorte de corrida armamentista no espaço sideral e nem existe prova de que ela está na iminência de despontar; b) afirmam que as atuais regras existentes já são suficientes para regulamentar a atividade espacial, incluindo a atividade militar (KUPLIC, 2014).

O fato, porém, é que, apesar das alegações norte-americanas de que não existe uma atual corrida armamentista espacial, ou sequer existe notícia de intenções neste sentido, as evidências apontam para o lado contrário.

Os últimos anos têm visto crescimento por parte dos Estados na alocação de recursos para o desenvolvimento e aperfeiçoamento de programas espaciais. Entre os novos atores que procuram se enveredar neste campo da tecnologia, China, Japão, Índia e até a Coreia do Norte, têm mostrado avanço em suas pesquisas (KUPLIC, 2014; VASANI, 2017).

E dentre os Estados acima citados são claras as intenções de futuro desenvolvimento de tecnologia militar aeroespacial por parte da China, Índia e Coreia do Norte, as quais têm mostrado diversas provas de uma intenção de militarizar o espaço sideral (BLOUNT, 2013; TALMADGE, 2016).

Aprofundando a segunda linha de defesa norte-americana, ela está baseada novamente na diferenciação de conceitos técnicos. Isto porque, segundo os EUA, existe uma distinção entre a militarização (militarization) e o armamento (weaponization) do espaço sideral. Enquanto o armamento do espaço sideral seria considerado como a colocação de armas em órbita (o que, novamente, estaria 
nas lacunas do Tratado do Espaço Sideral), a militarização seria um termo mais abrangente, que incluiria não somente o estacionamento de armas per si no espaço sideral, mas também a utilização de qualquer sorte de tecnologia que tenha fins militares, tais como os satélites.

Assim, os EUA defendem que não existe nenhuma sorte de impedimento entabulado por meio de um Tratado, e que a militarização do espaço sideral já é algo corrente desde a assinatura do Tratado do Espaço Sideral, pois não somente é uma atividade desempenhada por inúmeros Estados (WHITE, 2017), como também estaria intrinsecamente ligada a outras atividades não militares, o que impediria a restrição de seu uso. É o caso da utilização de satélites que, se por um lado podem servir para coletar informações sobre inimigos, por outro podem servir para realizar a transmissão de dados não militares, tais como bancários, acadêmicos ou de entretenimento (KUPLIC, 2014).

Outro ponto levantado pelo governo norte-americano é a falta de clareza que se tem para definir o que seria uma arma espacial, pois, na linha argumentativa dos EUA, qualquer objeto poderia ser considerado como arma espacial, pois todos teriam intrinsecamente a capacidade de causar danos, o que, por consequência, lhes possibilitaria serem abrangidos pelo conceito de arma. Desta maneira, não havendo um consenso sobre o que seriam armas espaciais, inviável seria realizar qualquer sorte de acordo sobre o assunto, muito menos a elaboração de um tratado (WHITE, 2017).

Como as resoluções adotadas pelo PAROS devem ocorrer por unanimidade, e como os EUA continuam se colocando como persistentes opositores de qualquer sorte de acordo sobre o assunto, a corrida armamentista espacial possui pista livre para desenvolver-se, prospecto este que não deve ser limado dos possíveis cenários possíveis (AL-RODHAN, 2018).

Assim se desdobra o atual panorama da questão: inexiste qualquer tipo de tratado que venha a, especificadamente, impor regras e/ou princípios acerca da exploração militar do espaço sideral, e há grande nicho de nações que vem se aproveitando desta anomia internacional para criar, aperfeiçoar e expandir os seus programas espaciais, os quais poderão, como consequência, possibilitar a exploração espacial militar.

Entretanto, apesar da falta de atitudes concretas por parte dos Estados que se faz presente, é importante observar que esta não é a única perspectiva para a segurança na Terra. Isto porque a própria criação e contínua implementação de um grupo de estudos para impedir a utilização do espaço sideral como uma nova arena de dominação militar (PAROS) demonstra, pelo menos $a$ priori, a vontade que alguns Estados têm de buscar uma solução pacífica e inclusiva para a utilização do espaço. Relembre-se, ainda, que os próprios EUA já tiveram postura mais inclinada a aceitar o estabelecimento de regras internacionais acerca do uso bélico do espaço sideral durante a administração Obama, o que pode indicar que existe real interesse em abordar o assunto; caso contrário haveria simplesmente a remoção de esforços neste sentido, como o fez a governo estadunidense na questão da proteção ambiental, retirando-se do Acordo de Paris sobre Mudança Climática.

Não obstante, a grande parte da produção científica sobre o assunto aponta, na verdade, para um discurso de legitimação, subsidiando a atual posição norte-americana de contínua exploração militar do espaço sideral. 
Ponto que se extrai de grande parte da produção científica consultada é que estas procuram ou realizar a defesa da posição de determinado Estado, ou então limitam-se a expor a situação como uma fotografia, somente caracterizando a situação sem apontar qualquer sorte de proposta concreta para tentar dar substância ao clamor de paz que os demais Estados almejam.

Com efeito, da produção ora analisada, somente alguns autores fazem, de maneira sucinta, análise sobre quais alternativas poderiam ser tomadas pelos Estados a fim de evitar a continuidade da Corrida Armamentista Espacial (KUPLIC, 2014; AL-RODHAN, 2018).

Outrossim, não somente a produção científica sobre o assunto deixa de apontar saídas concretas para o assunto, como também acaba por deixar a cargo dos Estados a resolução da contenda o que, por certo, não se tem mostrado como a maneira mais eficaz de atacar o assunto.

Foi este o sentimento, inclusive, que se pode extrair das razões utilizadas na $71^{\text {a }}$ Sessão, $15^{\circ}$ Encontro do Primeiro Comitê das Organizações das Nações Unidas. De fato, com exceção da já citada posição norte-americana e da posição controversa da Coreia do Norte, que, apesar de ter diversos indícios apontados para a construção de um programa bélico, afirma que seus objetivos são pacíficos, os demais Estados participantes se dividem em dois grupos: o primeiro defende a elaboração de regras obrigatórias para os Estados, ou seja, tratados (neste grupo incluem-se, por exemplo, a Rússia, Bangladesh, Venezuela e Suíça); o segundo defende a construção de uma carta de regras não obrigatórias que serviriam de guias para a atuação bélica no espaço sideral (compõem esta linha a União Europeia e Santa Sé).

Denota-se, por certo, que o panorama atual do tema inspira temores entre as nações, que podem escalar a ponto de que um pequeno conflito entre as nações em solo terrestre seja transposto para o espaço sideral, inaugurando uma nova era de guerra total, relembrando os auspícios existente durante a Guerra Fria.

\section{"Ottawa Process": conceito e aplicação da governança global à militarização do espaço sideral}

De evidente inspiração no conceito de governança global, o caso paradigmático - Ottawa Process - deu-se no tocante ao combate à proliferação e uso de minas antipessoais. No episódio, o uso do citado armamento vinha agravando de maneira brutal os conflitos existentes, a ponto de se considerar que tal tipo de instrumento militar acabava por infligir danos desnecessários não somente aos combatentes, mas também às populações dos países que se encontravam inseridos em tais combates.

Em que pesem os esforços até então existentes para a construção de um acordo de vontades com o escopo de extirpar este armamento, as negociações não vinham avançando, mantendo em nefasta paralisia a questão humanitária.

O ponto de virada sobre o assunto despontou quando, de maneira coordenada, diversas organizações não governamentais (ONGs) começaram a valer-se de estratégias para esclarecer 
o assunto à população em geral, demonstrando as suas consequências bárbaras e a falta de atuação dos Estados para a proibição e erradicação de tais armamentos.

Decorrendo diretamente da iniciativa destes novos atores, os Estados sentiram-se compelidos a firmar um acordo multilateral a fim de que tais clamores fossem atendidos, resultando, em 1997, na chamada Convenção sobre a Proibição do Uso, Armazenamento, Produção e Transferência de Minas Antipessoais e sobre a sua Destruição, também conhecida como Tratado de Ottawa. A tal método de atuação organizada realizada por atores não estatais foi atribuída a alcunha de "Ottawa Process" (MUTSCHLER, 2010).

Sem se distanciar muito da temática trazida à baila pelo Tratado de Ottawa, verifica-se que a exploração e transformação do espaço sideral em um novo palco de batalhas acaba por elevar os níveis de insegurança mundial a patamares nunca antes experimentados, haja vista que um conflito em tal arena produzirá certamente danos em todos os Estados.

A base para a exploração bélica no espaço sideral está na indústria armamentista, a qual detém especial interesse acerca do tema. De fato, apesar da gravidade do assunto, inexiste até a presente data qualquer espécie de legislação que especificamente venha a estabelecer limites ao avanço militar no espaço sideral, acabando, por via reflexa, a permitir aos Estados beligerantes uma via para a propagação de pesquisas e empreendimento de recursos nesta senda (GOPALAKRISHNAN, MURTHI, PRASAD, 2008).

É certo, porém, como já colocado acima, no âmbito das Organizações das Nações Unidas vários mecanismos têm sendo utilizados para tentar encontrar alternativas a fim de se evitar a militarização do espaço sideral, sendo os mais referendados aqueles desenvolvidos no âmago do COUPOS e o no PAROS (LING, 2011).

Entretanto, a crítica geral dos estudiosos do tema se traduz na falta de vontade política dos Estados para o estabelecimento de um acordo que impeça taxativamente a exploração bélica do espaço. Como visto, tal impasse se dá principalmente em razão de atuação dos EUA, os quais, em sua travestida retórica de defesa de interesses nacionais, acabam por criar as condições ideias para uma corrida armamentista, tendo-se em vista o comportamento dos Estados em investirem em determinada área com o fim de não se verem superados pelos seus pares (KAMOCSAI, 2015).

Ainda que vozes dissonantes afirmem que uma nova corrida armamentista está longe de ocorrer, ou ainda que tal conceito advenha de um longínquo roteiro de filme hollywoodiano, a ameaça é de fato real (GOPALAKRISHNAN, MURTHI, PRASAD, 2008).

Fora do escopo do Direito, diversos jornalistas e articulistas dos mais diversos Estados e inclinações políticas já vêm produzindo material acerca do assunto, assinalando a já existência de condições para o início de tal escalada bélica (TALMADGE, 2016; VASANI, 2017).

E, não obstante a movimentação existente no mundo acadêmico, a sociedade civil encontra-se amplamente desabastecida de informações sobre a matéria. Não somente inexiste qualquer sorte de engajamento acerca do assunto, como também não se produz material com o fito de se aclarar o assunto para a sociedade.

E a situação é mais preocupante no Cone Sul, o qual tipicamente padece de pesquisadores e produção científica sobre temas mais complexos, com honrosas exceções (COCCA, 2002). 
E é neste ponto que a noção de governança global encontra sua raison d'être. Isto, pois seu núcleo está intimamente ligado ao conceito de participação ampliada, ou seja, governança pode ser compreendida como um conjunto de relações intergovernamentais, nas quais os mais diversos novos atores possuem espaço para expor e debater ideias (GONÇALVES, COSTA, 2011).

A governança global traz nova configuração ao poder, na medida em que ocorre sua divisão e compartilhamento entre Estados e outras entidades e organizações, e tornam-se necessárias novas instituições, caracterizadas por regimes internacionais. É importante destacar, porém, que governança não se refere apenas a novos arranjos institucionais, ou a simples mudanças na arquitetura das organizações. A Comissão das Nações Unidas sobre Governança Global, em relatório publicado em 1994, definiu governança de maneira bastante clara, ao apontar que ela é a "totalidade das diversas maneiras pelas quais os indivíduos e as instituições, públicas e privadas, administram seus problemas comuns" (COMISSÃO SOBRE GOVERNANÇA GLOBAL, 1996, p. 2).

$\mathrm{Na}$ realidade, a governança compreende quatro dimensões que, em conjunto, formam seu arcabouço (GONÇALVES, 2011): a) ela é meio, instrumento e processo capaz de produzir resultados eficazes diante de problemas e desafios globais; b) é exigida a participação ampliada nos processos de decisão, envolvendo não só a dimensão estatal como também organizações internacionais, empresas transnacionais e organizações não governamentais; c) há a permanente busca de consenso e persuasão nas relações e ações, muito mais do que a coerção e a obrigação de cumprir; d) a governança implica ainda em institucionalidade dos processos, na medida em que sua construção e prática exigem o estabelecimento e operação de regras, ou seja, instituições sociais capazes de designar papeis e guiar a interação dos vários agentes envolvidos, e ao mesmo tempo facilitar a cooperação e reduzir os problemas de ação coletiva.

A governança global não se resume, porém, a dar origem aos regimes internacionais e basear-se em seu funcionamento. De fato, a ideia de governança global é mais ampla do que a de regimes internacionais. A governança propaga a ideia de "entendimentos necessários quando há hiatos ou conflitos entre regimes, e, portanto, situa-se num plano acima deles” (GONÇALVES, 2011, p. 43). Por sua vez, os regimes internacionais seriam uma das maneiras de implementação da governança global, já que "na medida em que governança diz respeito à busca de solução de problemas comuns, os regimes seriam uma das possibilidades de promover a governança” (GONÇALVES, 2011, p. 43).

A ideia de governança global amoldar-se-ia melhor à questão da militarização do espaço sideral, especialmente quanto à presença e influência da participação ampliada, que pe uma de suas características intrínsecas, permitindo assim ampliar a discussão além de um pequeno círculo de participantes, os Estados.

Nesta linha de raciocínio, em que pese incipiente, alguns estudiosos vêm apontando, como possível maneira de se atingir o objetivo de evitar a militarização do espaço sideral, a disseminação de informações para a conscientização da população, com o fim de se criar um instrumento de pressão em desfavor dos sujeitos clássicos do Direito Internacional Público (MUTSCHLER, 2010; NADEAU, 2013).

Com essa finalidade, realizou-se interessante estudo em 2013, no Canadá, a fim de verificar qual o grau de influência que a exposição de informações sobre a militarização do espaço sideral pode 
causar em um grupo de pessoas. Registre-se que a exposição de tais informações se deu de maneira didática (através da exibição do documentário Pax Americana and the Weaponization of Space), aproximando o indivíduo das complexidades do assunto. A conclusão foi que o grupo alicerçado com as informações sobre a temeridade que uma disputa bélica sideral pode causar demonstrou claramente a sua consternação com o assunto, ratificando a hipótese de que o tema somente não ocupa uma posição mais destacada perante a população em razão de simples falta de disseminação de informação (NADEAU, 2013).

As pesquisas citadas vêm apontando para uma nova via de abordagem do assunto, valendo-se da participação popular, claramente inspirado nos preceitos de governança global, através do citado "Ottawa Process".

Não há dúvida de que o processo de governança global vem inspirando debate de ideias em áreas em que os Estados se mostram desinteressados ou receosos de desempenhar o seu papel, seja porque se veem tomados por amarras políticas, seja por uma maior e invisível teia de interesses que restrinja suas atuações.

Interessante se observar, neste sentido, que tanto MUTSCHLER (2010) como NADEAU (2013), mesmo se interessando pelo mais amplo debate do assunto e sugerindo que este pode ser um fórum de conhecimentos, mostram-se receosos quanto à efetividade do "Ottawa Process" no campo da militarização do espaço sideral.

Isto porque ambos os estudiosos concordam que, apesar de haver campo a ser explorado tendo como o guia a governança global, a situação pré-existente no "Ottawa Process" diverge fundamentalmente da ora analisada. Enquanto que, no processo que deu nome ao Tratado de Ottawa, os mais importantes Estados se convenceram da importância de sua atuação no sentido de evitar o uso e a proliferação das minas antipessoais, obstáculo basilar se coloca sobre o tema em estudo. A tal obstáculo nomeiam-se os Estados Unidos da América.

De fato, enquanto na elaboração do tratado de 1995 os Estados Unidos encabeçavam a lista de Estados que foram conscientizados e partiram para uma atuação mais humanitária, neste caso a posição norte-americana é irremediavelmente contrária aos interesses pacíficos, em especial com a atual guinada em sua política capitaneada pelo republicano Donald Trump.

Como analisado, os norte-americanos defendem de maneira aguerrida que a questão da militarização do espaço sideral nada mais é do que outro campo em que sua soberania nacional (assim como de seus aliados) deve sobrelevar aos interesses mundiais. A questão de segurança nacional, pedra de toque na estrutura da política externa dos EUA, atinge com a corrida armamentista espacial um novo patamar, cujas consequências são efeitos cruéis contra a humanidade.

A contínua atuação estadunidense em empreender esforços para a militarização do espaço acaba por levar a um esforço de outras potências em também lograr esforços para continuar investindo neste viés armamentista.

Entretanto, mesmo diante deste difícil quadro, que tem raízes nas teorias realistas, baseadas em termos de poder, aplicadas de modo automático nos temas de segurança nacional, algumas lições podem ser extraídas do "Ottawa Process" e dos estudos realizados por MUTSCHLER e NADEAU. 
Primeiramente, a necessidade de melhor se conscientizar a população civil é imperiosa. Ainda que os Estados, a priori, não se vejam compelidos a realizar algum tipo de mudança em sua política de defesa, o fato é que a discussão de ideias e pontos de vista é necessária para trazer da penumbra assunto que, ao mesmo tempo, se afiança de vital importância para a manutenção da vida e tão relegado a discussões estatais. Não é crível que, diante dos entraves que se colocam no caminho da paz, os esforços sejam esmorecidos, mas sim devem ter uma nova injeção de ânimo, aumentando vagarosamente a pressão em face dos Estados e a conscientização da sociedade civil.

Em segundo lugar, e em direta correlação com a primeira lição, é necessário que haja uma atuação coordenada e conjunta da sociedade, da academia, das organizações não governamentais e think tanks, para que os esforços não sejam pulverizados sem atingir os objetivos pretendidos. A atuação em conjunto deve ser inteligente e desprovida de paixões, e erigida sobre estudos técnicos, inclusive indicando quais seriam os pontos ou áreas mais suscetíveis de ser influenciados para se alcançar o fim pretendido, qual seja, o fim da exploração militar no espaço sideral.

Não se olvide, contudo, que outras fontes podem servir aos propósitos de evitar a exploração militar do espaço sideral. Neste ponto é importante observar que o regime que trata da Antártica possui algumas similaridades que podem servir de substrato paradigmático para a questão do espaço.

De fato, ambos os regimes (Espaço Sideral e Antártida) possuem em seu bojo a ideia de não militarização e de utilização pacífica de tais ambientes (AUST, 2010, p.327-328). Isto porque o núcleo duro dos regimes vai além da utilização pacífica, pois é esperado que o uso dos espaços e ambientes possa atingir fins científicos que venham a atender a humanidade como um todo. De certo, a proposta de utilização pacífico-científica vai de encontro aos propósitos bélicos que encontram-se esgueirando o espaço sideral.

Entretanto, ainda que o regime da Antártida demonstre semelhanças com o regime do Espaço Sideral é necessário observar que o se pretende com o presente artigo não é realizar uma análise comparativa entre regimes, mas sim buscar compreender como a forma de abordagem e consecução do Tratado de Ottawa pode ser utilizada a fim de trazer novo paralelo ao impasse existente na questão espacial.

A governança global, como meio e processo de solução de problemas, afigura-se como forma de buscar soluções para a questão, principalmente se utilizada como mais uma via de pressão, desta vez social, a fim de direcionar os Estados à conclusão de entendimento sobre a utilização pacífica do espaço sideral.

O Tratado de Ottawa pode servir como paradigma da atuação dos demais atores à resolução da questão em voga, tendo em vista que também se ocupava em tratar de tema que, apesar de recorrente nos conflitos humanos, ainda era relegado a uma posição de menor destaque, tratando-se de clara designação de assunto de alta política a ser tratado como de baixa política. A proposta que se defende não é a de análise comparativa entre existentes regimes internacionais (aqui incluindo-se o da Antártida), mas sim verificar como as negociações para a construção de um instrumento internacional podem ser reutilizadas ou ao menos servir de inspiração para que sejam alcançados novos paradigmas.

A perspectiva da governança global visa trazer à tona questões que pelas mais diversas razões não são tratadas pelos Estados, porém são discutidas em outros círculos e por outros atores. 
E, conforme já referendado, diferentemente da questão dos regimes internacionais, a governança global traz em si uma ideia mais ampla de participação, a qual teve marcante impacto na discussão e construção do Tratado de Ottawa.

Trazer a conscientização da população funciona como o primeiro passo para com que esta possa se ver apta a discutir qualquer espécie de assunto. Assim como a atuação de diversas organizações não-governamentais foi imprescindível para o desenvolvimento do tema perante a população civil no que tange às minas antipessoais, a utilização desta mesma via pode ser vista como um caminho para alcançar-se o primeiro estágio de conscientização populacional, momento o qual é seguido de um debate mais aprofundado sobre o tópico.

\section{Conclusão}

O presente artigo pretendeu explorar, ainda que de maneira preliminar, qual seria a correlação entre os conceitos balizadores da governança global e militarização do espaço sideral.

Procurou-se, inicialmente, trazer à baila um breve histórico da corrida espacial e como esta veio a desaguar na atual corrida armamentista espacial que atualmente sonda os noticiários. Posteriormente, procurou-se explicar como a governança global pode ser importante instrumento nos estudos e discussões sobre o tópico, demonstrando como pode se dar uma atuação mutatis mutandi do chamado "Ottawa Process".

Diante das considerações realizadas sobre a possível correlação sobre o tema, procurou-se evidenciar como a governança global pode ser um meio eficaz para se alcançar o objetivo da pacificação do espaço sideral. E a conclusão que se chegou, ao mesmo passo em que não procura eliminar outras vias, destaca a importância de seus mecanismos e instrumentos.

Entendemos que, quanto maior a gama de artifícios e ferramentas existam, maior é a probabilidade de se alcançarem os resultados desejados. A governança global, conceito plástico e advindo dos atuais tempos modernos e líquidos, se destaca com ímpar relevância na consecução dos problemas do século XXI.

A existência de problema ou assunto não pode ser eternamente mistificada, criando-se inúmeros empecilhos e entraves que impossibilitem, sequer, o debate da questão, que pela sua natureza estaria restrito aos interesses de poder dos Estados. A militarização do espaço sideral, por certo, não deve ser restrita aos debates diplomáticos e a portas fechadas, mas deve ser considerada diante de uma série de linhas, as quais, por certo, estão baseadas nas ações dos atores não estatais, corroborando a necessidade de uma atuação mais inclusiva.

Procurou-se, desta maneira, destacar que, diferentemente do defendido por vários Estados, nenhuma matéria deve estar infensa à discussão mais ampla no cenário internacional, sem participação ampliada, e não se pode esperar uma solução deus ex machina para a militarização do espaço quando as discussões clássicas de alongam por décadas sem sequer ter sido realizado qualquer tipo de avanço mais substancial. Portanto, a governança global é e deve ser ponto de partida para um debate inclusivo, trazendo novos conhecimentos, técnicos e políticos, sobre o tema. 


\section{Referências bibliográficas}

AL-RODHAN, Nayef. Weaponization and Outer Space Security. Durham University. Disponível em: $<$ https://www.globalpolicyjournal.com/blog/12/03/2018/weaponization-and-outer-space-security>. Acesso em 04 out 2018.

AUST, Anthony. Handbook of International Law. Cambridge: Cambridge Press, 2010.

BLOUNT, P.J. The Shaping of "Peaceful Purposes": What North Korean Space Activities Can Tell Us about the Heart of Space Security Law. In: Procedings of The International Institute of Space Law, 2013, Beijing. Hague: Eleven International Publishing. 2013. p. 537-543

COCCA, María de las Mercedes Esquivel de. "Militarization of Space”. In: 45 Proc. on L. Outer Space 216, 2002. Disponível em: <https://heinonline.org/HOL/Page?handle=hein.space/pininsl0045\& collection=intyb\&id=236\&startid=\&endid=246>. Acesso em 04 out 2018.

COMISSÃO SOBRE GOVERNANÇA GLOBAL. Nossa Comunidade Global. Relatório da Comissão sobre Governança Global. Rio de Janeiro: Ed. FG, 1996.

GONÇALVES, Alcindo. Regimes internacionais como ações da governança global. In: Meridiano 47 vol. 12, n. 125, mai.-jun. 2011 [p. 40 a 45]. Disponível em: <http://periodicos.unb.br/index.php/ MED/article/view/3311/3502>. Acesso em $14 \mathrm{dez} 2018$.

GONÇALVES, Alcindo. COSTA, José Augusto Fontoura. Governança global e regimes internacionais. São Paulo: Almedina, 2011.

GOPALAKRISHNAN, V. MURTHI, KRS. PRASAD, MYS. "Weaponization of Outer Space and Impact on Peaceful Uses". In: 51 Proceedings of the International Institute of Space Law, 249, 2008. Disponível em: <https://heinonline.org/HOL/Page?handle=hein.space/pininsl0051\&collection $=$ intyb\&id=299\&startid=\&endid=310>. Acesso em 04 out 2018.

KAMOCSAI, Peter. Why the U.S. Should Be a Leader in Space Weaponization, 10 Jan. 2015. Disponível em: <http://spacenews.com/commentary-why-the-u-s-should-be-a-leader-in-spaceweaponization/>. Acesso em 04 out 2018.

KUPLIC, Blair Stephenson. “The Weaponization of Outer Space: Preventing an Extraterrestrial Arms Race”. North Carolina Journal of International Law and Commercial Regulation, vol. 39, n. 4, Summer, 2014. Disponível em: <http://scholarship.law.unc.edu/cgi/viewcontent.cgi?article=20 $11 \&$ context $=$ ncilj $>$. Acesso em 04 out 2018 .

LING, Yan. "Prevention of Outer Space Weaponization under International Law: A Chinese Lawyer's Perspective". In: 4 Journal of East Asia and international law 271, 2011. Disponível em: <https:// heinonline.org/HOL/Page?handle=hein.journals/jeasil4\&collection=journals\&id=266\&startid= \&endid=285>. Acesso em 04 out 2018.

MUTSCHLER, Max M. "Ottawa in Space? Reversing the Burden of Proof Regarding Space Weapons". European Space Policy Institute, Vienna, n. 33, Jun. 2010. Disponível em: <https://www.files.ethz. ch/isn/124686/espi\%20perspectives_33.pdf>. Acesso em 04 out 2018.

NADEAU, François. "Examining the effects of anti-space weaponization arguments in the media: Some experimental findings from Canada". Space Policy, Amsterdam, v. 29, n. 1, p. 67-75, Fev. 2013. https://doi.org/10.1016/j.spacepol.2012.11.004. Acesso em 04 out 2018. 
PAX Americana and the Weaponization of Space. Direção: Denis Delestrac. Produção: Jeremy Edwardes, Lucie Tremblay e Brice Garnier. Roteiro: Denis Delestrac e Harold Crooks. Narração: Mikela Jay. França/Canada: Canadian Broadcasting Corporation (CBC), Radio Canada, Télévision française de l'Ontario (TFO), ARTE France, Centre National du Cinéma et de l'image animée (CNC), COFILOISIR, Hong Kong and Shanghai Banking Corporation (HSBC), 2010. Disponível em: <https://www.youtube.com/watch?v=KVPhcOKoukQ>. Acesso em 04 out 2018

PINDJACK, Peter. The Eisenhower Administration's Road to Space Militarization. Pittsburgh: University of Pittsburgh, 2011. Disponível em: <http://d-scholarship.pitt.edu/7698/1/Thesis_ PindjakPeter2011Updated.pdf>. Acesso em 04 out 2018.

TALMADGE, Eric. "Sanctions won't stop our space race. North Korea sets sights on the moon". The Guardian, London, 04 Aug. 2016. Disponível em: <https://www.theguardian.com/world/2016/ aug/04/sanctions-wont-stop-our-space-race-north-korea-sets-sights-on-the-moon $>$. Acesso em 04 out 2018.

VASANI, Harsh. "How China Is Weaponizing Outer Space". The Diplomat, Tokyo, 19 Jan. 2017. Disponível em: <https://thediplomat.com/2017/01/how-china-is-weaponizing-outer-space/>. Acesso em 04 out 2018.

WHITE, Angela. Space War: The Militarization \& Weaponization of Space. Michigan State University: College of Law, 16 Feb. 2017. Disponível em: <https://www.msuilr.org/msuilr-legalforumblogs/2017/2/16/space-war-the-militarization-weaponization-of-space>. Acesso em 04 out 2018. 